\title{
O NEABI e a educação para as relações étnico-raciais ${ }^{1}$
}

\author{
El NEABI y la educación para las relaciones étnico-raciales
}

NEABI and education for ethnic-racial relations

\author{
Luci Helena Silva Martins ${ }^{2}$ \\ Valesca Rodrigues de Souza ${ }^{3}$
}

\begin{abstract}
Resumo
Este artigo foi apresentado ao Congresso Internacional Online de Estudos sobre Cultura 2020 com o intuito de promover uma discussão acerca de como o Núcleo de Estudos, Pesquisas e Extensão Afro-Brasileiros e Indígenas (NEABI) do Instituto Federal do Norte de Minas Gerais (IFNMG), sob a ótica do reconhecimento social, pode ser observado como instância de resistência para a educação para as relações étnico-raciais. Entende-se que a discussão sobre a educação não pode se dar sem uma análise crítica das condições sob as quais se desenvolveram os mecanismos educacionais, tendo em conta um contexto, sobretudo cultural, em que a educação de "qualidade" sempre fora reservada a uma elite dominante e utilizada como instrumento de mantença dos privilégios que engendram e perpetuam a injustiça social no Brasil. Por isso, a relevância em se observar a atuação do NEABI/IFNMG enquanto instância de luta por reconhecimento social.
\end{abstract}

Palavras-chave: NEABI; educação; relações étnico-raciais; cultura; reconhecimento social.

\section{Resumen}

Este artículo fue presentado al Congreso Internacional en Línea de Estudios sobre Cultura 2020 para promover una discusión sobre cómo el Centro de Estudios, Investigación y Extensión Afrobrasileños e Indígenas (NEABI) del Instituto Federal del Norte de Minas Gerais (IFNMG), desde la perspectiva del reconocimiento social, puede verse como una instancia de resistencia a la educación para las relaciones étnico-raciales. Se entiende que la discusión sobre la educación no puede tener lugar sin un análisis crítico de las condiciones bajo las cuales se desarrollaron los mecanismos educativos, teniendo en cuenta un contexto, especialmente cultural, en el que la educación de "calidad" siempre ha sido reservada para una élite dominante y utilizada como instrumento para mantener los privilegios que engendran y perpetúan la injusticia social en Brasil. Por lo tanto, la relevancia de observar el desempeño del NEABI/IFNMG como una instancia de lucha por el reconocimiento social.

Palabras clave: NEABI; educación; relaciones étnico-raciales; cultura; reconocimiento social.

\begin{abstract}
This article was presented at the International Online Congress of Studies about Culture 2020 aiming at promoting a discussion about how the Center of studies, research and extension Afro- Brazilian and Indigenous (NEABI) of the Federal Northern Institute (IFNMG), from the perspective of social recognition, can be seen as an instance of resistance for education and for ethnic-racial relations. We understand that the discussion about education cannot happen without a critical analysis over the conditions, in which the educational devices were developed, in a context, mainly cultural, where "quality" education has always been reserved to a dominant class
\end{abstract}

\footnotetext{
${ }^{1}$ Artigo apresentado ao Congresso Internacional Online de Estudos sobre Cultura, na modalidade online, 2020.

${ }^{2}$ Doutora em Serviço Social; professora do Programa de Pós-graduação em Desenvolvimento Social e do curso de Serviço Social da Universidade Estadual de Montes Claros (Unimontes); Montes Claros; Minas Gerais; Brasil; lucihelenam@yahoo.com.br.

${ }^{3}$ Mestre em Educação; professora do Instituto Federal do Norte de Minas Gerais (IFNMG) - Campus Montes Claros; Montes Claros; Minas Gerais; Brasil; valesca.souza@ifnmg.edu.br.
} 
and used as an instrument to keep privileges that perpetuate social injustice in Brazil. Thus, it is relevant to observe the actions of NEABI/IFNMG as an instance of fight for social recognition.

Key words: NEABI, education, ethnic-racial relations, culture, social recognition.

\section{Introdução}

Tratar da educação para as relações étnico-raciais é buscar conhecer as múltiplas questões relacionadas à formação da cultura brasileira e das etnias que participaram e participam em condições desiguais da construção do país. Para tanto, torna-se necessário compreender a educação pelo viés histórico e social, considerando a realidade de um país escravocrata extremamente carente do debate acerca do racismo estrutural que permeia os processos educacionais das instituições de ensino tradicional.

Entende-se que a discussão sobre a educação não pode se dar sem uma análise crítica das condições sociais e culturais sob as quais se desenvolveram os mecanismos educacionais, balizando-se no fato de que a educação de "qualidade" sempre fora reservada a uma elite dominante que, ainda, a utiliza como instrumento de mantença dos privilégios que engendram e perpetuam a injustiça social no Brasil. Por isso, a necessidade de se observar os processos para construção das relações étnico-raciais no âmbito educacional.

Objetivando subsidiar a discussão aqui proposta fora realizada uma pesquisa bibliográfica considerando as seguintes áreas: reconhecimento social, desenvolvimento social, cultura, educação para as relações étnico-raciais, políticas públicas, Institutos Federais. Também, fora realizada uma pesquisa documental que envolveu as leis $n^{\circ} 10.639 / 03$ e $n^{\circ}$ 11.645/08 e os documentos institucionais que regulamentam os Institutos Federais e o NEABI no âmbito do IFNMG, traçando uma linha do tempo da criação do NEABI/IFNMG. Assim, este artigo discutirá educação e cultura no Brasil e a constância da luta por uma educação antirracista.

\section{Educação e cultura no Brasil}

Não é possível falar de educação no Brasil sem considerar as injustiças sociais que a constituíram e ainda a permeiam, o que requer uma reflexão acerca da escola pública e do acesso a esta, numa sociedade alicerçada na exclusão social e racial. Neste contexto indagase: a que parcela da população brasileira fora e ainda é destinada a formação profissional? Ou melhor, a que parcela da população negou-se historicamente o acesso à educação? 
Sobre a experiência da educação para índios e negros no Brasil, Petronilha Beatriz Gonçalves e Silva (2011) pontua:

\begin{abstract}
Voltemos às considerações sobre as tentativas de assimilação, por meio da escola, dos povos submetidos política e ideologicamente aos sistemas de colonizadores europeus. Na experiência brasileira, além do que passou com os indígenas, deve-se ter presente a situação dos africanos escravizados, de seus filhos e descendentes. A eles foi negada a possibilidade de aprender a ler, ou se lhes permitia, era com o intuito de incutir-lhes representações negativas de si próprios e convencê-los de que deveriam ocupar lugares subalternos na sociedade. Ser negro era visto como enorme desvantagem, utilizava-se a educação para despertar e incentivar o desejo de ser branco. Além de cor de pele, destaca Santos (2000), tratava-se também de lugar a ocupar na sociedade, de poder (SILVA, 2011, P. 21).
\end{abstract}

Além da negação da educação, aos índios e negros lhes foi inculcada a vergonha por suas diferenças, que não condiziam com o padrão do branco europeu. Retirados de sua cultura e impedidos de praticar suas crenças lhes foi negada a possibilidade de se expressarem e, portanto, a possibilidade de ação tanto no espaço privado quanto no espaço público, aqui retomando Hannah Arendt (1997), quando trata da ação política do homem. Vê-se, portanto, um processo de escravização pautado na exploração desses povos e, sobretudo, na mantença dos indivíduos como subjugados e marginalizados.

\begin{abstract}
Até o século XIX, a presença de negros escravizados na vida brasileira era entendida como uma necessidade, pois grande parte dos processos relacionados ao trabalho produtivo estava associada às atividades desenvolvida por estes indivíduos. Desta forma, era recorrente a preocupação com mecanismos que possibilitassem a sua utilização como trabalhadores escravizados, mas que ao mesmo tempo permitissem o controle de suas influências na dinâmica social. Foi em meio a este dilema que a educação foi vinculada à população negra livre, adquirindo as feições de um instrumento de controle capaz de definir lugares precisos para esses indivíduos no espaço social (FONSECA, 2011, p. 63-64).
\end{abstract}

Gabriel Cohn (2016), discorrendo sobre a dominação sob a ótica de Weber, coloca que o exercício do poder se dá pela violência e para que haja um exercício persistente do poder é necessário que as ações dos dominadores sejam legitimadas pelos pacientes tornando suas ações de natureza legal.

Negar a educação a negros e índios, ou mesmo, ofertar-lhes uma educação que os mantivesse em papéis subalternos socialmente, era uma forma de torná-los passivos e incapazes de progredir, inculcando-lhes a legitimação da dominação, numa tentativa constante de transformá-los em co-autores do processo de violência que viviam.

Silva (2011) frisa que, apesar de medidas para impedir que a população negra frequentasse a escola, em meados do século XIX, em Minas Gerais, escravizados e libertos 
tinham algum acesso às letras por meio de salas-escolas mantidas, particularmente, por letrados com vocação para ensinar. No entanto, quando o ensino tornou-se público a população negra diminuiu nos bancos escolares. "Como se vê, a instrução pública, entre nós, nasce excludente, racista" (Silva, 2011, p. 22). Neste contexto, iniciativas individuais levaram às populações excluídas a educação, uma vez que as políticas públicas não lhes consideravam parte da sociedade.

É pertinente trazer à baila a situação do povo negro após a abolição da escravidão em 13 de maio de 1888. A assinatura da Princesa Isabel não aboliu o sofrimento dos escravos ao libertá-los das algemas da escravidão sem apoio do Estado. Não fora direcionada aos exescravos políticas públicas que, de fato, os inserissem na sociedade imperial; ao contrário, foram postos à margem sem educação, formação profissional ou mesmo um pedaço de terra que lhes garantisse o sustento. Tal situação fez com que perdurassem práticas de exploração análogas ao trabalho escravo até a atualidade.

A situação educacional de negros e indígenas no Brasil escancara um contexto de negação e exclusão que inviabilizaram e, pela realidade da educação hoje, ainda inviabiliza a emancipação e a ação política desses povos.

\begin{abstract}
O que dizer dos direitos privados de indivíduos que são também cidadãos? [Como os interesses e direitos privados de alguém podem ser reconciliados com o que se tem direito a exigir dele enquanto um cidadão?] (...) realmente a liberdade, a vida política, a vida do cidadão - esta "felicidade pública" de que falei - é um luxo; uma felicidade adicional para a qual se torna apto apenas depois de as solicitações do processo vital terem sido satisfeitas. Desse modo, se falamos de igualdade, a questão é sempre a seguinte: quanto temos de transformar as vidas privadas dos pobres? Em outras palavras, quanto dinheiro temos de dar a eles para torná-los aptos a desfrutar da felicidade pública? Educação é muito bom, mas o que importa mesmo é dinheiro. Somente quando puderem desfrutar do público é que estarão dispostos e aptos a fazer sacrifícios pelo bem público. Requerer sacrifícios de indivíduos que ainda não são cidadãos é exigir deles um idealismo que eles não têm e nem podem ter em vista da urgência do processo vital. Antes de exigirmos idealismo dos pobres, devemos antes torná-los cidadãos: e isto implica transformar as circunstâncias de suas vidas privadas de modo que se tornem aptos a desfrutar do "público" (ARENDT, 1977, p. 106-107 apud CORREIA, 2008, p. 111) (grifos nossos).
\end{abstract}

Arendt (1977 apud Correia 2008) defende que a política se faz no espaço entre as pessoas, um espaço de comunicação onde a pluralidade ache lugar. Mas para que a política se concretize pela palavra partilhada, ou seja, para que a "felicidade pública" aconteça os homens dessa partilha devem dispor de conhecimento e condições para tal. Dessa maneira, é possível enxergar a dimensão da luta do povo negro para alcançar a esfera pública, ao passo que não dispunha sequer da satisfação de suas necessidades vitais.

Mediante tais apontamentos surgem algumas indagações: quem fez e faz parte da 
sociedade? Quem tem acesso à cultura? Ou melhor, quem a constrói?

Para Arendt (2011) a cultura de massa, tão discutida por intelectuais desde o século XX, "é a cultura de uma sociedade de massas" (ARENDT, 2011, p. 248). O ponto central é compreender que o denominador comum entre sociedade de massas e cultura de massas é a sociedade na qual as massas foram incorporadas.

Arendt (2011) recorda que o movimento da arte moderna foi a rebelião do artista contra a sociedade tal como era, e não contra uma sociedade de massas, ainda desconhecida. Assim, fala sobre cautela mediante críticas à cultura de massas em contraponto a Idade do Ouro de uma "sociedade boa e bem-educada". Ainda, lembra da superficialidade do conhecimento difundida na Europa do filisteísmo cultural e educado, cenário no qual a cultura adquiriu valor de esnobismo, tornando-se uma questão de status a apreciação da cultura.

A "boa sociedade" é aquela que provavelmente originou-se nas cortes europeias e restringiu-se aos salões nos séculos XVIII e XIX, possuidora de dinheiro e lazer para o devotamento à cultura, ou seja, a cultura se restringia a uma pequena parcela da população, situação que se modifica nos séculos XX e XXI com os direitos do trabalhador, que os libertava do fardo extenuante de uma jornada de trabalho de mais de doze horas, permitindolhes dedicação à cultura. Assim, a massa da população se incorpora à sociedade.

Arendt (2011) aponta como um dilema muito maior que o embate entre sociedade e cultura, que remonta as revoluções e o filisteísmo, o monopólio da cultura pela sociedade objetivando posição social e status.

Nessa luta por posição social a cultura começou a desempenhar enorme papel como umas das armas, se não a mais apropriada, para progredir socialmente e para "educar-se", ascendendo das regiões inferiores, onde a realidade estaria situada, para as regiões superiores e supra-reais onde o belo e o espírito estariam em seu elemento (ARENDT, 2011, p. 254).

A fuga da realidade por meio da arte e da cultura naquele momento foi fundamental para a insurgência do artista moderno contra seus próprios protetores, que temiam terem sua arte arrastada para o lugar do superficial e supérfluo tão apreciado naquele ambiente. Percebese a fuga do artista da própria ideia de provisoriedade, pois como afirma Arendt (2011, p. 255) "somente o que durará através dos séculos pode se pretender em última instância um objeto cultural".

Relembrando a ruptura entre as artes e a realidade no século XIX, Hannah fala que a recuperação criativa das artes se dá quando a "boa sociedade" perde seu domínio monopolizador sobre a cultura. Neste ínterim ocorre a desintegração da cultura, quando os 
objetos culturais perdem a faculdade original de comover e é tratado como "valor" numa sociedade comercial.

Arendt (2011) frisa que, enquanto a sociedade sente a necessidade da cultura e a consome como mercadoria, a sociedade de massas busca o divertimento. A cultura de massas surge quando a sociedade de massas se apodera de objetos culturais e, no processo vital da sociedade, consome os objetos culturais não somente comendo, mas destruindo-os. A preocupação não se funda na desintegração, mas sim no empobrecimento cultural.

Até aqui se observa a dissociação entre sociedade e cultura, bem como a crítica sobre a própria sociedade de massas (que não teve e não tem a mesma educação e tempo para o se dedicar à cultura que "boa sociedade") e, consequentemente, sua cultura. Tais dilemas se encontram com a política na medida em que, para Arendt, cultura e política se encontram numa mesma categoria, pois o que está em jogo é o julgamento na esfera pública que propicia o desenvolvimento do próprio gosto.

De qualquer maneira, podemos recordar aquilo que os romanos - o primeiro povo a encarar seriamente a cultura, à nossa maneira - pensavam dever ser uma pessoa culta: alguém que soubesse como escolher sua companhia entre homens, entre coisas e entre pensamentos, tanto no presente como no passado (Arendt, 2011, P. 281).

Entretanto, cabe frisar que o desenvolvimento da pessoa culta se assenta justamente no acesso à cultura, não se pode cobrar do homem participação na esfera pública pela palavra se o mesmo não teve em sua vida tempo e condições para deleitar-se com o conhecimento da arte, se o seu percurso no mundo se restringe tão somente à busca pela sobrevivência num corpo exaurido pelo trabalho. O desenvolvimento da capacidade de discernimento e a própria dialogicidade estão como num degrau acima do que este homem possa alcançar. Não está, portanto, preparado para a política, não teve acesso às construções culturais da esfera pública, porque na esfera privada importava-lhe sobreviver.

Contudo, aqui interessa aquilo que permanece no mundo para seu processo vital através da arte, ou ainda, pelas mãos do artista que, para Arendt (2011), é capaz de produzir objetos que pertencem inteiramente ao mundo, as obras de arte. Cabe enfatizar as lutas travadas pelo povo negro para entregar à posteridade sua criação, sua arte, sua cultura. Sangue e suor para que a ancestralidade seja conhecida dos que surgem para o novo.

Por isso, falar em arte para a educação que liberta e pensar a atuação do NEABI, que, sabe-se, utiliza a arte como fundo de desenvolvimento de projetos que visam a educação para as relações étnico-raciais, na busca mesmo por identidade e permanência da cultura negra. 
Educar por amor o mundo: a permanência do mundo repousa, então, na natalidade, na renovação incessante das gerações, no nascimento de homens novos que tenham cuidado com o mundo. Ou seja, que sejam capazes de renová-lo através de sua ação, susceptíveis assim a dar início a algo novo. [...]porém o exemplo do processo vital, do labor e do consumo, onde o homem se encontra completamente abandonado a si mesmo, a ação é efêmera e se consuma nela mesma. Nem a realização de grandes atos, nem o proferimento de grandes discursos deixam traços. É por esta razão que os homens novos sempre precisaram do homo faber, daquele que assegura a durabilidade do mundo através da reificação (COURTINE-DENAMY, 2004, p. 181).

A questão centra-se em deixar à posteridade uma produção cultural que possa servir a sua formação. Assim, no prólogo de sua obra "A condição humana" Arendt pontua que todo acontecimento vivido precisa da recordação para repassar: "e sem este acabamento pensado após o ato e sem a articulação realizada pela memória, simplesmente não sobrou nenhuma história que pudesse ser contada" (ARENDT, 2010, p. 3).

Essa busca trata também da impossibilidade do encontro com uma origem identitária africana única, uma vez que essa só pode ser feita pela construção de um passado recriado, de uma história inventada em solo brasileiro, [...] A reconstituição do passado que orienta a construção da identidade, se faz, assim, a partir da cultura brasileira e não da verdadeira e perdida origem étnica, familiar, e, em última instância, racial. Mesmo quando o negro se expressa para afirmar a negritude, a condição africana, não resta a ele fazê-lo senão como brasileiro. Ainda que o passado ancestral perdido seja a África pluriétnica, multicultural, o passado recuperável é aquele que o Brasil logrou incorporar na construção de uma nova civilização, passado que só pode ser inventado, memória recriada. (PRANDI, 2005, p. 172).

A luta do povo negro é pela sobrevivência de África no seio da sociedade brasileira, composta em sua maioria por pretos e pardos. Recuperar a cultura roubada, oportunizar a educação negada.

\subsection{A constância da luta por uma educação antirracista}

Muitos negros e negras foram essenciais para que a educação chegasse àqueles que estavam a margem da sociedade brasileira, fazendo chegar a esses uma possibilidade de transformação individual, social e coletiva. Dentre muitos heróis e heroínas destaca-se Abdias do Nascimento que, em 1944, período em que os negros só entravam nos teatros para limpeza do ambiente frequentado pelos brancos, criou o que pode ser considerado um dos maiores laboratórios de diversidade nas artes cênicas do Brasil, o Teatro Experimental do Negro, que mudou a vida de centenas de pretos e pardos (GELEDÉS, 2019).

O ativista recrutou domésticas, analfabetos, operários e desempregados, todos negros, para estudar teatro e construir peças. Neste processo acontecia tanto a alfabetização quanto a 
conscientização dos atores e atrizes como cidadãos da sociedade brasileira. Abdias deu vez e voz ao povo negro através da cultura teatral e da valorização das raízes africanas. "Abdias Nascimento foi poeta, ator, escritor, dramaturgo, artista plástico, professor universitário, político e ativista dos direitos civis e humanos das populações negras” (GELEDÉS, 2016). Seu legado de luta e resistência deixou conquistas imensuráveis para a população brasileira nos séculos XX e XXI, cujos frutos ainda florescem, como as cotas raciais e a comemoração ao dia da consciência negra.

Luiz Alberto Oliveira Gonçalves (2011) enfatiza que, a partir do século XX, o Brasil tomou cada vez mais consciência de que não era um país de democracia racial e, para desconstrução deste mito, foram essenciais os estudos de Florestan Fernandes, Roger Bastilde e Luiz Costa Pinto. Somou-se a esses estudos a atuação das organizações negras e uma parte da imprensa crítica que denunciavam o racismo vivenciado cotidianamente.

Muitas foram as conquistas dos povos negros e indígenas do século XIX até o século XXI. Como exemplo, cita-se a Conferência Mundial contra o racismo, discriminação racial, Xenofobia e Intolerâncias Correlatas, realizada em Durban, África do Sul, em 2001, que trouxe avanços nas discussões acerca da dinâmica das relações étnico-raciais no Brasil, considerando as diversas formas de discriminação racial vivenciadas pela população negra. Foi também um avanço a criação, em 2003, da Secretaria Especial de Políticas de Promoção da Igualdade Racial (SEPPIR) - que representou a materialização de uma histórica reivindicação do movimento negro em âmbito nacional e internacional. A questão racial foi, então, incluída como prioridade na pauta de políticas públicas do país, uma demonstração do tratamento que a temática racial passou a receber dos órgãos governamentais a partir daquele momento.

No ano de 2003, Joaquim Benedito Barbosa Gomes publica o artigo "O debate constitucional sobre as ações afirmativas", no qual expõe a situação do negro no Brasil frente a um sistema educacional segregador que, em detrimento de uma educação de qualidade para todos os brasileiros, utiliza-se de vários mecanismos para manter a hegemonia política, econômica e social da elite branca.

Este, também, foi o ano da promulgação da Lei $\mathrm{n}^{0} 10.639 / 03$, que estabelece a inclusão no currículo oficial da Rede de Ensino a obrigatoriedade da temática "História e Cultura Afro-Brasileira". Observa-se no cenário nacional um forte movimento para a quebra do silêncio, oportuno à elite brasileira, das questões relacionadas às condições de vida da população negra no Brasil. 
Segundo Gomes (2003) era necessária a união dos negros para adentrarem o espaço público como força política ou um governo com vontade de mudança social para "mudar o quadro de abandono, ostracismo e violenta exclusão a que os negros brasileiros são cotidianamente relegados" (Gomes, 2003, p. 15).

A lei $n^{\circ} 10.639 / 03$ e, posteriormente, a lei $n^{\circ} 11.645 / 08$, que ademais da cultura afrobrasileira inclui a temática indígena no currículo escolar, surgem de um percurso de lutas do Movimento Negro; sendo apresentadas como política pública amparada pelo Estado, visando o despertar da sociedade brasileira para a situação histórica do negro e do indígena no Brasil, adentrando em questões culturais, econômicas e sociais consolidadas na exclusão e no racismo.

São dezessete anos de um caminho que tem se mostrado sinuoso ante uma sociedade escravista e extremamente apegada aos privilégios, que nega os direitos do povo negro e indígena, cotidianamente.

\begin{abstract}
A implementação da Lei ${ }^{\circ}$ 10.639/03 e de suas respectivas diretrizes curriculares nacionais vem se somar às demandas do Movimento Negro, de intelectuais e de outros movimentos sociais, que se mantêm atentos à luta pela superação do racismo na sociedade, de modo geral, e na educação escolar, em específico. Estes grupos partilham da concepção de que a escola é uma das instituições sociais responsáveis pela construção de representações positivas dos afro-brasileiros e por uma educação que tenha respeito à diversidade como parte de uma formação cidadã. Acreditam que a escola, sobretudo a pública, exerce papel fundamental na construção de uma educação para a diversidade (Lino Gomes, 2011, p. 41).
\end{abstract}

Neste sentido convém destacar o papel fundamental dos docentes nas instituições de ensino (aqui enfatizando as Instituições Federais de Ensino Técnico enquanto lugar de fala), que já desenvolviam diversos projetos relacionados à educação para as relações étnico-raciais.

A partir de 2006 a SEPPIR proporcionou diversos momentos de construção coletiva e orientou as Instituições Federais de Ensino Técnico para a criação dos Núcleos de Estudos Afro-brasileiros (NEAB), sendo que a questão indígena já fazia parte das discussões entre essas Instituições de ensino e a secretaria supracitada. Após a promulgação da lei $\mathrm{n}^{\circ}$ 11.645/08, a SEPPIR orientou a criação de comissões responsáveis por organizar a criação dos referidos núcleos em instituições de ensino que ainda não contavam com o mesmo.

Entendendo o NEABI como política pública, convém discorrer sobre o lócus desta discussão, o Instituto Federal do Norte de Minas Gerais (IFNMG), enquanto instituição de oferta da educação profissional e, portanto, espaço da tensão, vez que a história da educação profissional no Brasil foi marcada pela dualidade entre saber e trabalho. 
O ensino profissional foi direcionado às classes menos favorecidas, sendo os primeiros aprendizes de ofícios no Brasil os índios e os escravos no período da colonização e, posteriormente, os órfãos e desvalidos amparados pela Escolas de Aprendizes e Artífices, em 1909. Partindo daí os IFs passaram por muitas transformações: 1930 - Liceus Industriais; 1942 - Escolas Técnicas Federais (ETFs); a partir de 1978 - Centros Federais de Educação Tecnológica (Cefets); 2008 - Institutos Federais (Ifs) (Souza, 2010) 4 .

Frigotto (2007) diz que este período de transformações marca a transição de um ciclo de reformas educativas embasado na ideologia do capital humano para um ciclo de reformas orientado pela ditadura do capital. A educação profissional que inicialmente tinha como objetivo a criação de força de trabalho braçal passa, no período de transformação para CEFET, a atender aos interesses do capital, seguindo as demandas da globalização a partir da política adotada pelo Estado.

Tal ideologia persiste na transformação das instituições de educação profissional em IFs, instituídos pela Lei № 11.892 , de 29 de dezembro de 2008, que criou 38 unidades localizadas em todos os estados da Federação, instituições de ensino com natureza jurídica de autarquia, que gozam de autonomia administrativa, patrimonial, financeira, didáticopedagógica e disciplinar.

Essa racionalidade fez e faz parte de muitos discursos. Com uma roupagem redentorista, muitas ações políticas voltadas para a educação se travestiram de ações progressistas, porém representaram exclusão dos mais pobres e cerceamento de uma formação cidadã plena. Essas marcas foram presentes ao longo da história nas políticas compensatórias para a educação profissional. A formação de mão-de-obra, dita qualificada, seria uma forma de manter a sociedade coesa e produtiva, e, assim, todos se sentiriam felizes e produtivos (MENDES, 2013, p. 50-51).

As tensões, que circundam a formação para o exercício da cidadania e a formação de mão-de-obra para o mercado, suscitam a dicotomia intelectual/manual, temática amplamente discutida por Kuenzer (1999), Ciavatta (2006), Frigotto (2007) e Carvalho (1999); os quais discutem as políticas públicas voltadas para a educação profissional e o reducionismo do conhecimento para essa formação, donde emergem termos como "exclusão", "inclusão", "cidadania", "emancipação", dentre outros.

Apesar do vínculo capitalista, o Ministério da Educação (MEC) pontua que os IFs atendem a necessidade de se institucionalizar a educação profissional como política pública, uma vez que possuem como foco a equidade, a justiça social, a competitividade econômica e a geração de novas

\footnotetext{
${ }^{4}$ Nem todas as instituições de educação profissional seguiram as mesmas configurações, algumas passaram de Escola Agrotécnica (EAF) a IF, enquanto outras de Centro Federal de Educação Tecnológica (CEFET) a IF. Ainda, temos instituições que não aderiram à chamada pública para transformação em IF.
} 
tecnologias: "Esse é o elemento diferencial que está na gênese da constituição de uma identidade social particular para os agentes e instituições envolvidos neste contexto [...]" (MEC, 2009, p. 07).

A criação dos IFs, tal como preconizado em seus documentos norteadores, é uma política pública que envolve a questão social, porém, ao lado da justiça social também são apresentadas vertentes vinculadas à competitividade econômica, permitindo entrever a base da política econômica neoliberal no processo de transformação dessas instituições. Daí a importância da consolidação do NEABI enquanto instância que prima pelos estudos e projetos que despertem o olhar da comunidade escolar para as relações étnico-raciais, mas sobretudo enquanto ponto de debate das questões atuais dos povos negros e indígenas.

Para visualizar, ainda que de forma rasa, o processo temporal de criação do NEABI, esta pesquisa fez um recorte para o NEABI do IFNMG - Campus Montes Claros e, por meio de pesquisa documental, construiu uma linha do tempo:

2011 - comissão responsável pela organização do NEABI no âmbito do IFNMG;

2015 - comissão responsável pela elaboração do regulamento do NEABI;

2016 - aprovação nos órgãos colegiados superiores do regulamento do NEABI, regido por regulamento próprio em consonância com a Lei de Diretrizes e Bases da Educação Nacional LDB $n^{\circ}$ 9.394/1996, a Lei $n^{\circ} 10.639 / 2003$, o Parecer CNE/CP $n^{\circ}$ 03/2004, a Lei $n^{\circ}$ 11.645/2008 e a Resolução CP/CNE n01/2004, que fundamentam a educação para as relações étnico-raciais no Brasil;

$2017-1^{\mathrm{a}}$ portaria do NEABI do IFNMG - Campus Montes Claros.

O conhecimento do processo de implantação e consolidação do NEABI no IFNMG é certamente uma pesquisa necessária, pois possibilitaria entrever o próprio desenvolvimento das relações étnico-raciais no contexto educacional, o que propõe-se como investigações futuras.

É importante salientar que o NEABI, em 2010, já constava em documentos institucionais como o Regimento Geral, e sua criação e consolidação demandou tempo e disposição de servidores que assumiram o núcleo como instância fundamental para o desenvolvimento de uma educação antirracista.

No artigo $2^{\circ}$ do regulamento do Núcleo de Estudos, Pesquisas e Extensão Afrobrasileiros e Indígenas (NEABI) do IFNMG, publicado em 2016 e revisado em 2019, consta:

Art. $2^{\circ}$. O Núcleo de Estudos, Pesquisas e Extensão Afro-Brasileiros e Indígenas do Instituto Federal do Norte de Minas Gerais, denominado NEABI/IFNMG, criado por portaria instituída em cada unidade de ensino, vinculados a Direção-Geral, e à Diretoria de Assuntos Estudantis e Comunitários/Núcleo de Ações Inclusivas NAI/DAEC, tem a finalidade de promover a discussão das relações étnico-raciais na sociedade brasileira, de forma a contribuir para a promoção da equidade racial, bem 
como assessorar na inclusão, no currículo oficial da rede de ensino, da temática "História e Cultura Afro-Brasileira e Indígena", nos termos da Lei no 11.645/2008 e da Resolução CP/CNE n ${ }^{\circ}$ 01/2004, pautada na construção da cidadania, por meio da valorização da identidade étnico-racial, especialmente de negros, afrodescendentes e indígenas (IFNMG, 2019).

Esta discussão assenta-se, especialmente, na prática dos NEABIs para minimizar a realidade histórica na oferta da educação tida como "braçal" a uma camada da população considerada "desvalida", e, portanto, excluída de uma educação plena que os leve à emancipação no sentido mesmo de "libertação", tal como apregoa Freire (1996). O trabalho teórico e prático do NEABI é de suma importância para a educação das relações étnico-raciais na sociedade brasileira, uma vez que auxilia na formação de sujeitos emancipados, críticos e capazes de se manifestarem publicamente enquanto cidadãos.

Maria Aparecida Colares Mendes (2013), apresentando a "cidadania plena e emancipada", destaca uma educação solidária que deve ir além das demandas do mercado e do capital, devendo, pois, ocupar-se de processos formativos que empreendam a construção de uma nova ordem econômica que diminua os abusos do acúmulo do poder econômico. "Essa nova ordem econômica e essa nova educação são, pois, mais do que um processo limitado a uma perspectiva produtivista das relações sociais e de trabalho. Constituem, assim, uma educação voltada para a transformação e pela luta contra as injustiças sociais" (MENDES, 2013, p. 86).

É para a luta contra as injustiças sociais que o NEABI e, consequentemente, as instituições de ensino precisam se colocar. $\mathrm{Na}$ busca constante por uma educação antirracista que seja capaz de transformar a sociedade brasileira ainda presa pelas correntes do racismo e da exclusão.

É necessário iniciar um processo de reestruturação das bases pedagógicas a partir de discussões abertas sobre as relações étnico-raciais, afirmando as instituições de ensino enquanto espaço múltiplo de caráter emancipador, oportunizando aos envolvidos vivenciarem o respeito à diversidade.

\section{Conclusão}

Sob o prisma da educação ideológica Paulo Freire (1996) coloca:

A capacidade de penumbrar a realidade, de nos "miopizar", de nos ensurdecer que tem a ideologia faz, por exemplo, a muitos de nós, aceitar docilmente o discurso cinicamente fatalista neoliberal que proclama ser o desemprego no mundo uma desgraça do fim do século. Ou que os sonhos morreram e que o válido hoje é o 
"pragmatismo" pedagógico, é o treino técnico-científico do educando e não sua formação de que já não se fala. Formação que, incluindo a preparação técnicocientífica, vai mais além dela (FREIRE, 1996, p. 126).

É para a formação mais além, para a emancipação dos sujeitos, que está o papel do NEABI nas instituições de ensino. O debate contínuo das práticas e ações direcionadas à educação para as relações étnico-raciais e para a análise deste contexto a partir da teoria do reconhecimento social torna-se cada vez mais relevante.

Marco Vanzulli (2018) apresenta as relações intersubjetivas apregoadas por Honneth, especificamente as não entendidas, para criar uma teoria crítica da sociedade. Para Honneth, essas relações são naturalmente positivas e, em seus conflitos e dinâmicas, se apresentam como formadoras de identidades. Tais aspectos demonstram o pensamento político e social da modernidade.

\begin{abstract}
A parte central da obra de Honneth consiste numa explicação dos três modelos de reconhecimento intersubjetivos: amor, direito e reputação ou solidariedade, uma tipologia analisada segundo uma pesquisa, que ele próprio chama de fenomenológica, a com a intenção de controlar empiricamente as três formas de reconhecimento detectadas. O reconhecimento como amor indicaria a inteira esfera da afetividade, como o laço com algumas poucas pessoas. Honneth cita Hegel, que bem definiu esse primeiro estágio do reconhecimento com a expressão de "ser si mesmo em um estranho" (VANZULLI, 2018, p. 22).
\end{abstract}

O trabalho do NEABI para inserção da temática das relações étnico-raciais no ambiente escolar, visando a emancipação dos sujeitos, pode ser analisada por meio da teoria do reconhecimento, no sentido mesmo da afetividade que move os trabalhos dos sujeitos que compõe esse núcleo. Assim como o direito que embasa as ações e a solidariedade para com os povos negros e indígenas. Por isso, inferir sobre a ação social como a "realização criativa do novo", apregoada por Honneth" (VANZULLI, 2018, p. 25).

As ações realizadas pelo NEABI podem ser vistas como o novo; contudo, a implementação das leis que incluem a história e a cultura afro-brasileira e indígena em pauta nas instituições de ensino encontra barreiras, por vezes, de difícil transposição, visto que não se trata somente de inserir a discussão no contexto escolar, mas de reestruturar as bases pedagógicas num movimento de resgate histórico fundamentado teoricamente, objetivando uma real modificação do processo de ensino-aprendizagem que deve caminhar para a valorização dos conhecimentos dessas culturas, fazendo acontecer as transformações sociais necessárias. 
Por isso, observar o NEABI enquanto lócus de ocupação e resistência, local de aquilombamento, termo lindamente cunhado por Conceição Evaristo (2020):

\author{
Tempo de nos aquilombar \\ É tempo de caminhar em fingido silêncio, \\ e buscar o momento certo do grito, \\ aparentar fechar um olho evitando o cisco \\ e abrir escancaradamente o outro. \\ É tempo de fazer os ouvidos moucos \\ para os vazios lero-leros, \\ e cuidar dos passos assuntando as vias \\ ir se vigiando atento, que o buraco é fundo. \\ É tempo de ninguém se soltar de ninguém, \\ mas olhar fundo na palma aberta \\ a alma de quem lhe oferece o gesto. \\ O laçar de mãos não pode ser algema \\ e sim acertada tática, necessário esquema. \\ É tempo de formar novos quilombos, \\ em qualquer lugar que estejamos, \\ e que venham os dias futuros, salve 2020, \\ a mística quilombola persiste afirmando: \\ "a liberdade é uma luta constante"
}

Aquilombar o NEABI é unir pessoas, pensamentos, ideais e ações visando resistir através da ocupação do espaço escolar, histórica e socialmente negado ao povo negro. É ajuntar na busca incessante pelo reconhecimento social que pode, de fato, efetivar a coletividade na sociedade brasileira em toda sua diversidade.

\title{
Referências
}

ARENDT, Hannah. [1958]. A condição humana. Rio de Janeiro: Forense Universitária, 2010.

Entre o passado e o futuro. São Paulo: Perspectiva, 2011.

Origens do totalitarismo. São Paulo: Companhia das Letras, 2012.

BELLONI, Isaura; MAGALHÃES, Heitor de; SOUSA, Luzia Costa de. Metodologia de avaliação em políticas públicas: uma experiência em educação profissional. 4 ed. São Paulo: Cortez, 2007. 96 p. (Coleção Questões da Nossa Época, v. 75).

BRASIL. Lei $n^{o}$. 11.892, de 29/12/2008. Institui a Rede Federal de Educação Profissional, Científica e Tecnológica, cria os Institutos Federais de Educação, Ciência e Tecnologia, e dá outras providências. Diário Oficial da União, Brasília, DF, Brasília - DF, 30 dez. 2008. 
Ministério da Educação. Histórico da Educação Profissional. Disponível $\mathrm{em}:\langle$ http://portal.mec.gov.br/setec/arquivos/centenario/historico_educacao_profissional.pdf $>$. Acesso em: 17 ago. 2009.

Ministério da Educação. Secretária de Educação Profissional e Tecnológica. Concepções e Diretrizes - Instituto Federal de Educação, Ciência e Tecnologia. Brasília DF, 2008. Disponível em: 〈http://portal.mec.gov.br/setec/arquivos/pdf3/ifets_livreto.pdf〉. Acesso em: 11 nov. 2008a.

COHN, Gabriel. Weber, Frankfurt: teoria e pensamento social. 1 ed. Rio de Janeiro: Azougue, 2016.

CORREIA, Adriano. A questão social em Hannah Arendt: apontamentos críticos. Rev. Filos., Aurora, Curitiba, v. 20, n. 26, p.101-112, jan./jun. 2008.

COURTINE-DENAMY, SYLVIE. O cuidado com o mundo: diálogo entre Hannah Arendt e alguns de seus contemporâneos. Belo Horizonte: Editora UFMG, 2004.

EVARISTO, Conceição. Tempo de nos aquilombar. Disponível em: https://www.xapuri.info/cultura/tempo-de-nos-aquilombar/ . Acesso em: 15 jul. 2020.

FONSECA, Marcus Vinicius. Educação e controle em relação à população negra de Minas Gerais no século XIX. FONSECA, Marcus Vinicius et al. Relações étnico-raciais e educação no Brasil. Belo Horizonte: Mazza Edições, 2011. Pp. 61-91

GOMES, Nilma Lino. Diversidade étnico-racial: por um projeto educativo emancipatório. FONSECA, Marcus Vinicius et al. Relações étnico-raciais e educação no Brasil. Belo Horizonte: Mazza Edições, 2011. Pp. 39-59.

GONÇALVES, Luiz Alberto Oliveira. Pensar a educação, pensar o racismo no Brasil. FONSECA, Marcus Vinicius et al. Relações étnico-raciais e educação no Brasil. Belo Horizonte: Mazza Edições, 2011. Pp. 93-143

MINISTÉRIO DA EDUCAÇÃO. Conselho Nacional de Educação. Parecer n ${ }^{\circ}$ CNE/CP 003, de 10 de março de 2004. Diretrizes Curriculares Nacionais para a Educação das Relações Étnico-Raciais para o Ensino de História e Cultura Afro-Brasileira e Africana. Brasília, DF, 2004.

MINISTÉRIO DA EDUCAÇÃO. Secretaria de Educação Continuada, Alfabetização e Diversidade. Educação Antirracista: caminhos abertos pela Lei Federal 10.639/03. Brasília, DF: Ministério da Educação, Secretaria de Educação Continuada, Alfabetização e Diversidade, 2005.

MORETTI, Gianna Alessandra Sanchez. Igualdade como Diversidade no Direito à Educação: erradicando a discriminação étnico-racial no sistema de ensino brasileiro. 2017. Tese (Doutorado em Direito) - Centro de Direito, Estado e Constituição, Universidade de Brasília. Brasília, 2017, p.177.

NASCIMENTO, ABDIAS DO. Quando um herói nacional é negro: Abdias do Nascimento e a História que não aprendemos. 2019. Disponível em: https://www.geledes.org.br/quando-um- 
heroi-nacional-e-negro-abdias-do-nascimento-e-a-historia-que-nao-aprendemos/. Acesso em: 29 jun. 2020.

PIROMALLI, Eleonora. Teoria crítica e psicanálise: um processo de aprendizado de Adorno, através de Habermas, até Honneth. Desigualdade e reconhecimento: atualidade da teoria crítica de Axel Honneth. Antônio Dimas Cardoso (org.).Montes Claros: Unimontes, 2018.

PRANDI, Reginaldo. Segredos guardados: orixás na alma brasileira. São Paulo: Companhia das Letras, 2005.

SILVA, Caetana Juracy Resende da (org.). Institutos Federais lei 11.892, de 29/11/2008: comentários e reflexões. Natal: IFRN, 2009. 70 p.

SILVA, Petronilha Beatriz Gonçalves e. Aprender, ensinar e relações étnico-raciais no Brasil. FONSECA, Marcus Vinicius et al. Relações étnico-raciais e educação no Brasil. Belo Horizonte: Mazza Edições, 2011. Pp 11 - 37.

VANZULLI, Marco. Exposição crítica da teoria do reconhecimento de Axel Honneth. Desigualdade e reconhecimento: atualidade da teoria crítica de Axel Honneth. Antônio Dimas Cardoso (org.).Montes Claros: Unimontes, 2018. 